\section{耍 Heighten Science \\ P U B L I C I T I O N S Corporation ISSN \\ 2577-140X}

*Address for Correspondence: AYENA Koffi Didier, MD 08 BP 8986 Lomé, Togo, West Africa, Tel: 002289011 5963; Fax: 00228222260 02; E-mail: didier23fr@yahoo.fr

\section{Submitted: 15 November 2016}

Approved: 16 February 2017

Published: 17 February 2017

Copyright: @ 2017 Ayena KD, et al. This is an open access article distributed under the Creative Commons Attribution License, which permits unrestricted use, distribution, and reproduction in any medium, provided the original work is properly cited.

Keywords: Cataract; MSICS; ECCE; Africa; Togo

\title{
A Comparative Study of Anatomic and Functional Outcomes of Two Surgical Techniques of Cataract at Lome
}

\author{
Ayena KD ${ }^{1 *}$, Santos KAM ${ }^{2}$, Vonor $\mathrm{K}^{2}$, Amedome $\mathrm{KM}^{3}$, Wodome \\ $A^{4}$, Strauss ${ }^{5}$, Nagbe $\mathrm{YE}^{1}$, Koffi-Ametooyona $\mathrm{A}^{1}$ and Balo $\mathrm{K}^{2}$ \\ ${ }^{1}$ Hospital of Be at Lomé, Texas, USA \\ ${ }^{2}$ Sylvanus Olympio's teaching hospital at Lome, Texas, USA \\ ${ }^{3}$ Teaching hospital of Kara, Texas, USA \\ ${ }^{4}$ Jean-Paul II Eye Clinic of Lome, Texas, USA \\ ${ }^{5}$ Medical Chief of Mercy Ship, Texas, USA
}

\section{SUMMARY}

Aim: To compare the anatomical and functional outcomes of cataract surgery with manual small incision cataract surgery (MSICS) to those of extracapsular cataract extraction (ECCE) in Lome.

Patients and Methods: A prospective study involved two groups of patients who underwent ECCE (group 1) and MSICS (group 2) by the same surgeon in the same conditions in different periods. Complications and visual results to the 45 th postoperative day were compared.

Results: At the 45 th postoperative day, $60 \%$ of operated eyes of the ECCE group (G1) and $83.9 \%$ in the group of MSICS (G2) had uncorrected visual acuity greater than or equal to $3 / 10$. Through the pinhole, these proportions increased to $73.3 \%$ for $\mathrm{G} 1$ and $92.2 \%$ for $\mathrm{G} 2$. Visual acuity was less than $1 / 10$ in $4.4 \%$ for $\mathrm{G} 1$ and $1.1 \%$ for G2. The vitreous loss was observed in proportions of $3.8 \%$ for $\mathrm{G} 1$ and $3.3 \%$ for G2. During follow-up, the three main early postoperative complications were inflammation (13.9\%), corneal edema (13.3\%), and the pigment dispersion (7.2\%) in G1 and corneal edema (9.4\%), pigment dispersion (8.3\%) and hypertonia (6.6\%) in $\mathrm{G} 2$

Conclusion: Two cataract extraction techniques offer the same level of safety in intraoperative period. However, MSICS has certain advantages over the ECCE and would be an alternative technique in developing countries.

\section{INTRODUCTION}

Cataract is a partial or total clouding of the lens that causes decrease of visual acuity (DVA). Its main causes are senescence, intraocular inflammation, metabolic troubles, trauma, and radiations.

According to WHO, cataract is the first cause of blindness in the world [1]. It is $50 \%$ of all of avoidable blindness causes. Developing countries pay a heavy price of that problem. Surgery is the only one treatment currently available. Cataract surgery techniques have improved considerably from intracapsular extraction, phacoemulsification surgery and Laser femtosecond surgery. The last gives well anatomical and functional results, but it is still a very expensive procedure for developing countries. These last decades, a new technique has emerged almost taking the phacoemulsification without the use 
of ultrasound [2]. It is the surgical technique of cataract by manual sutureless small incision cataract surgery (MSICS). This technique also gives well anatomical and functional results [2-8].

MSICS is recently introduced in Togo and has been more and more widely used since 2010. In a previous study, the astigmatism has been evaluated in cataract surgery by MSICS [9]. The purpose of this study was to compare the anatomical and functional results of cataract surgery by MSICS to those of extracapsular cataract extraction (ECCE) with suture in Lome.

\section{PATIENTS AND METHODS}

It is a prospective, descriptive and comparative study on the patients operated for cataract by ECCE from September 2009 to February 2010 (G1) and by MSICS from September 2010 to February 2011 (G2) in a denominational eye center in Lome. The surgeon was the same for both groups of patients and had practiced each technique at least on 150 patients before the study. The surgeon knew ECCE surgery during his resident training and when Mercy Ship came in Togo for humanitarian health care, he learned MSICS technique and practiced it for the patients. So in any period of the study there was no choice to the surgeon.

To be eligible each patient must give an informed consent. He or she had to be at least 40 years old and have no history of ocular pathology that can lead to the decreased of visual acuity (DVA) apart from cataract. Therefore, patients with a pterygium, a corneal scar or macular disease, optic atrophy were excluded. Each patient must be operated by the same surgeon in the same eye center in the same conditions and have to follow-up postoperative control appointments until the forty-fifth day. Any patient were prepared as follow for the surgery:

- Patient's installation on a surgical stretcher

- Skin and ocular surface disinfection with povidone-iodine

- Peribulbar anesthesia with $5 \mathrm{ml}$ of lidocaine mixed with adrenaline $2 \%$.

The surgical technique was chosen by single blinded process. In ECCE technique the main steps were [10]:

- Taking the upper right muscle

- upper limbic incision for 10 to $12 \mathrm{~mm}$

- capsulotomy with the cystotome

- Total core of the lens bloc extraction by the process of pressure against pressure

- viscoelastic injection in the anterior chamber and the capsular bag

- insertion of a standard PMMA lens in the capsular bag

- wound closure of five separated sutures with nylon filament 10/0.

- preparation of the anterior chamber

- Intraocular injection of cefuroxime $1 \mathrm{mg} / 0.1 \mathrm{ml}$

- sub-conjunctival injection of dexamethasone mixed with gentamicin

- instillation of antibiotic drops

- occlusive bandage on a monocular hull.

\section{In MSICS technique the main steps were [10]:}

- conjunctival disinsertion

- scleral cauterization

- $\quad$ superior scleral incision reverse and curvilinear 6.5 to $7.5 \mathrm{~mm}$ whose apex is located $1.5 \mathrm{~mm}$ from the limbus 
- construction of a sclero-corneal tunnel

- -temporal set incision

- $\quad$-opening in the anterior chamber on a width of $8.5 \mathrm{~mm}$

- capsulotomy

- hydrodissection

- -dislocation of the nucleus in anterior chamber

- -extraction of the lens with forceps of Snellen

- cortex manual washing with cannula of Simcoe

- -viscoelastic injection in the anterior chamber and the capsular bag

- -insertion of a standard PMMA lens in the posterior chamber

- preparation of the anterior chamber

- intraocular injection of cefuroxime $1 \mathrm{mg} / 0.1 \mathrm{ml}$

- injection of dexamethasone mixed with gentamicin

- instillation of antibiotic drops

- an occlusive bandage on a monocular hull.

The implants inserted were of standard power of 21 or 22 diopters depending on what was available since no implant power calculation was made prior to surgery. In each group there was no hospital stay. The follow up was made regularly by the team. The team reported any complication to the surgeon for it management. The post operative medication was topical corticosteroid mixed with antibiotic during 30 days.

The studied variables were age, sex, visual acuity assessed in a well-light room using a Snellen scale placed at 5 meters, and incidents per operative and postoperative complications. The encountered difficulties were related to the study framework which was not yet available for biometer computation power of the intraocular lens.

Data collected on a standardized plug were analyzed using Epi Info version 6.0 software. The results are presented as averages and statistical $\mathrm{Chi}^{2}$ test has been used with a threshold of significance $\mathrm{P}<0,05$.

\section{RESULTS}

In each group there were 180 operated eyes, totaling 360 operated eyes of 360 patients. The female sex was more represented in each group 103 and 119 with a sex ratio of 0.75 and 0.51 respectively in G1 and G2 (Table 1). Table 2 summarizes the distribution of patients by age. The most represented age groups were those above 70 years (G1) and 61 to 70 years (G2). No patient was left aphakic. Uncorrected visual acuity (UVA) of preoperative (Figure 1) was less than 1/10 in 96\% in G1 and $90.5 \%$ in G2. The difference between the two groups was not significant ( $\mathrm{p}=0.8390$ ). Intraoperative, vitreous loss occurred in 7 cases in G1 (3.8\%) and 6 cases in G2 (3.3\%).

During the monitoring, the 3 main early postoperative complications were (Table 3) inflammation (13.9\%), corneal edema (13.3\%) and the pigment dispersion $(7.2 \%)$ in $\mathrm{G} 1$, and corneal edema (9.4\%), pigment dispersion $(8.3 \%)$ then the hypertonia $(6.6 \%)$ in G2. Secondary cataract was the main late complication observed in $8.3 \%$ and $6.1 \%$ respectively in G1 and G2 (Table 4).

On the eighth day (D8) post operative, the UVA was less than $1 / 10$ in $11.1 \%$ and $3.3 \%(p=0.0548)$ respectively in G1 and G2. The UVA was higher than $3 / 10$ in $43.3 \%$ to $59.4 \%$ ( $p=0.0598$ ) respectively in G1 and G2 (Figure 2). On D8 the two techniques provided statistically the same UVA. At pinhole, the VA was less than $1 / 10$ in $5.6 \%$ and $1.7 \%(\mathrm{p}=0.0271)$ then was higher than $3 / 10$ in $61.1 \%$ and $81.1 \%(\mathrm{p}=0.0654)$ respectively in G1 and G2 (Figure 3). 
Table 1: Distribution of patients by gender.

\begin{tabular}{|c|c|c|c|c|}
\hline \multirow{2}{*}{} & \multicolumn{2}{|c|}{ Group 1 } & & Group 2 \\
\cline { 2 - 5 } & Number & Percentage(\%) & Number & Percentage (\%) \\
\hline Male & 77 & 42,8 & 61 & 33,9 \\
\hline Female & 103 & 57,2 & 119 & 66,1 \\
\hline Total & 180 & 100 & 180 & 100 \\
\hline
\end{tabular}

Table 2: Distribution of patients by age.

\begin{tabular}{|c|c|c|c|c|}
\hline \multicolumn{3}{|c|}{ Group 1} & \multicolumn{2}{|c|}{ Group 2} \\
\hline \multicolumn{2}{|c|}{ Number } & \multirow{2}{*}{$\begin{array}{c}\text { Percentage (\%) } \\
10,5\end{array}$} & \multirow{2}{*}{$\begin{array}{c}\text { Number } \\
22\end{array}$} & \multirow{2}{*}{$\begin{array}{c}\text { Percentage (\%) } \\
12,2\end{array}$} \\
\hline $40-50$ & 19 & & & \\
\hline $51-60$ & 39 & 21,7 & 53 & 29,4 \\
\hline $61-70$ & 54 & 30,0 & 63 & 35,0 \\
\hline Over 70 & 68 & 37,8 & 42 & 23,4 \\
\hline Total & 180 & 100 & 180 & 100 \\
\hline
\end{tabular}

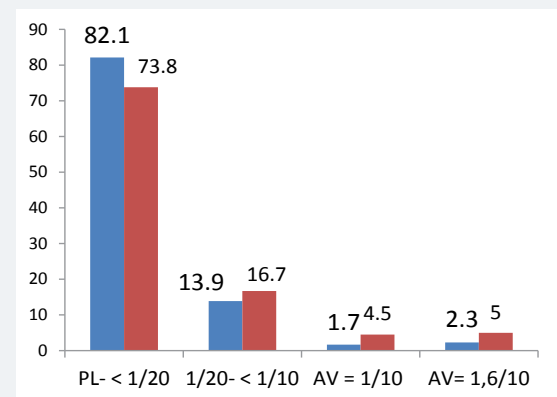

Figure 1: Distribution of eyes according to the preoperative uncorrected visual acuity (UVA). $\mathrm{PL}=$ Light perception; $\mathrm{AV}=$ Visual acuity

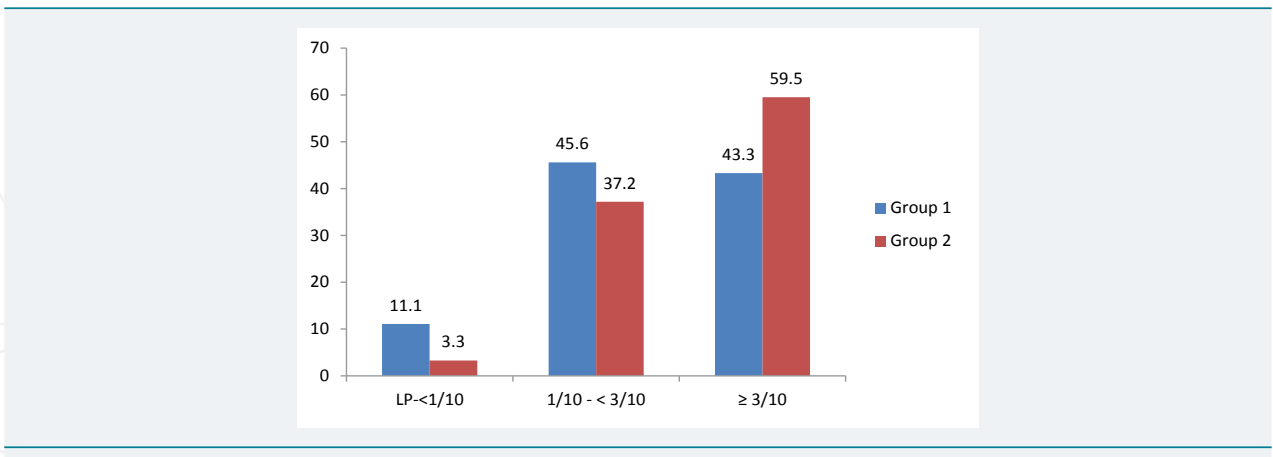

Figure 2: Distribution of far uncorrected visual acuity on D8.

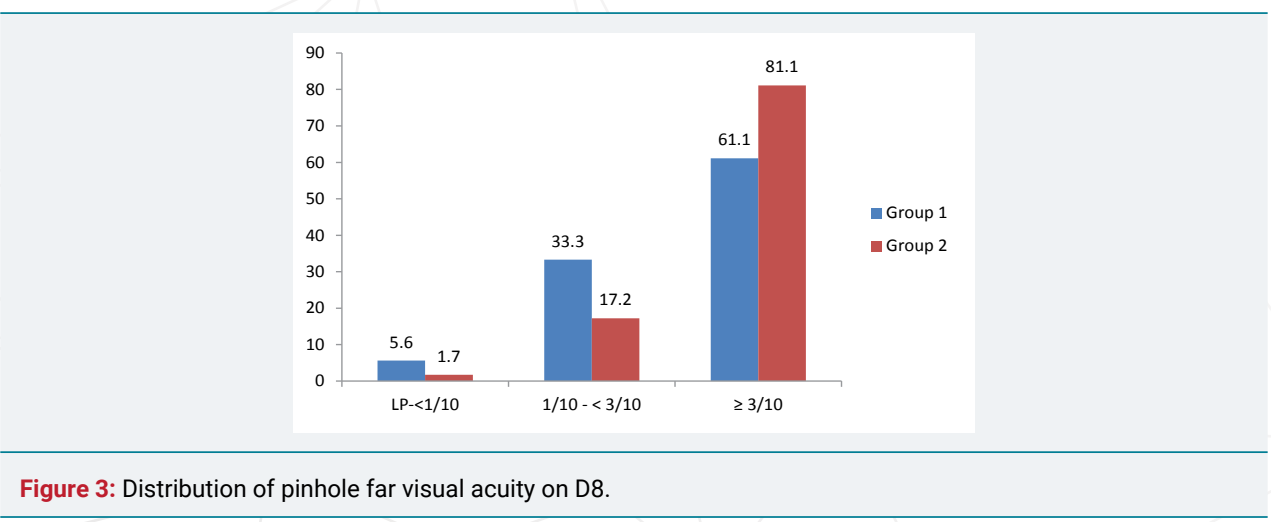


Table 3: Distribution of early postoperative complications.

\begin{tabular}{|c|c|c|c|c|}
\hline & \multicolumn{2}{|c|}{$\begin{array}{c}\text { Group 1 } \\
\text { Number Percentage(\%) }\end{array}$} & $\begin{array}{c}\text { Group } \\
\text { Number Percentage(\%) }\end{array}$ \\
\hline Hypertonia & 6 & 3,3 & 12 & 6,6 \\
\hline Corneal edema & 24 & 13,3 & 17 & 9,4 \\
\hline Inflammation & 25 & 13,9 & 6 & 3,3 \\
\hline Residues masses & 8 & 4,4 & 2 & 1,1 \\
\hline Hyphema & 7 & 3,9 & 2 & 1,1 \\
\hline Pigment dispersion & 13 & 7,2 & 15 & 8,3 \\
\hline implant moving & 1 & 0,5 & 0 & 0 \\
\hline Pupillary ascension & 6 & 3,3 & 1 & 0,5 \\
\hline
\end{tabular}

Table 4: Distribution of late complications

\begin{tabular}{|c|c|c|c|c|}
\hline \multirow[b]{2}{*}{ Permanent corneal edema } & \multicolumn{2}{|c|}{$\begin{array}{c}\text { Group } 1 \\
\text { Number Percentage(\%) }\end{array}$} & \multicolumn{2}{|c|}{$\begin{array}{c}\text { Group } 2 \\
\text { Number Percentage(\%) }\end{array}$} \\
\hline & 1 & 0,5 & 0 & 0 \\
\hline Inflammation & 1 & 0,5 & 0 & 0 \\
\hline Posterior synechiae & 4 & 2,2 & 0 & 0 \\
\hline Secondary cataract & 15 & 8,3 & 11 & 6,1 \\
\hline
\end{tabular}

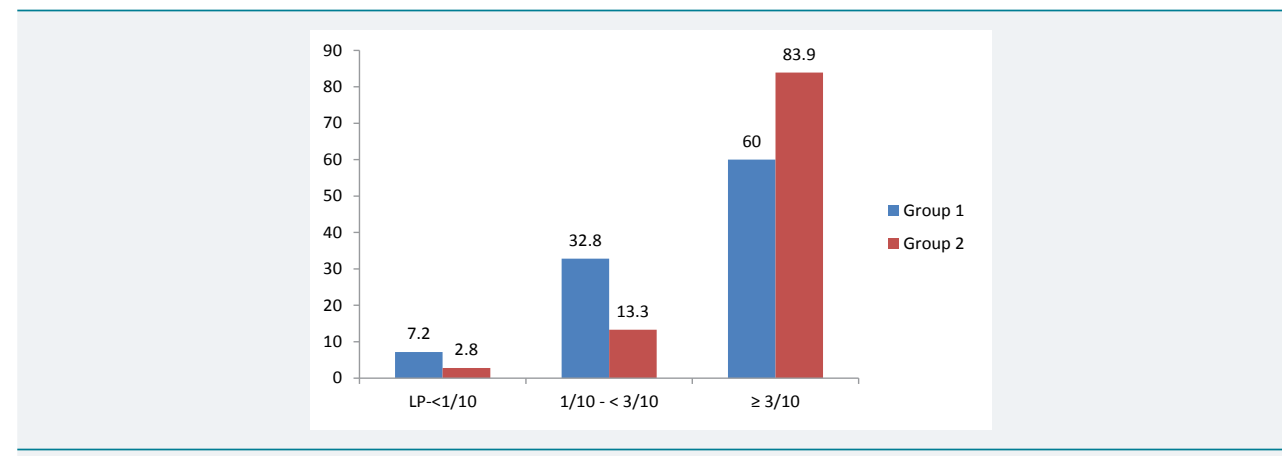

Figure 4: Distribution of far uncorrected visual acuityon D45.

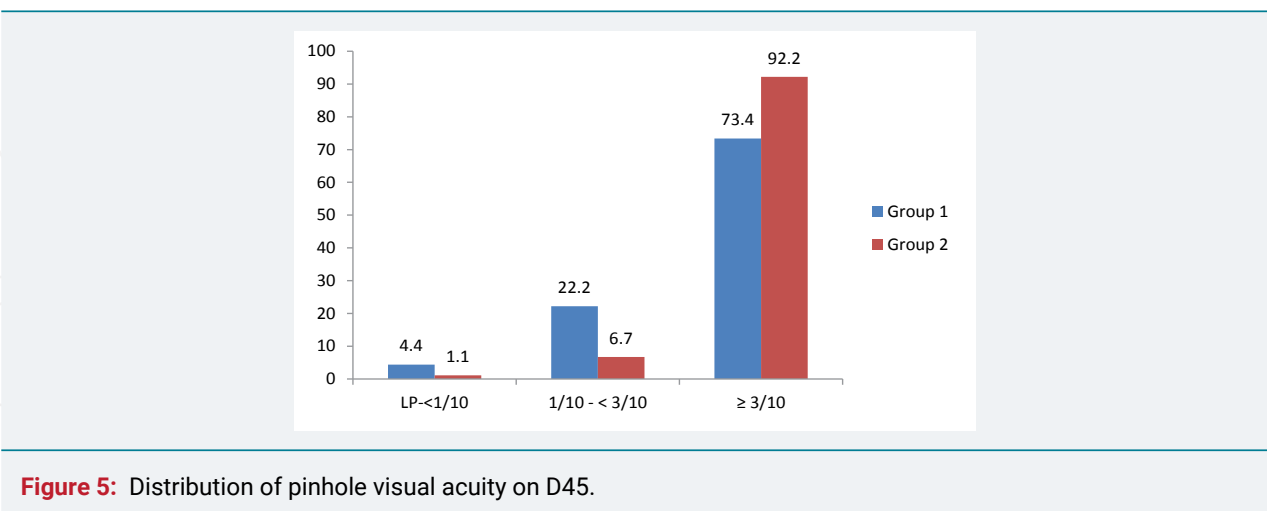

On the forty-fifth day (D45) post-operative, the UVA was less than $1 / 10$ in $7.2 \%$ and $2.8 \%(\mathrm{p}=0.0268)$ respectively in G1 and G2. The UVA was higher than $3 / 10$ in $60 \%$ and $83.9 \%(p=0.0952$ ) respectively in G1 and G2 (Figure 4). At pinhole, the UVA was less than $1 / 10$ in $4.4 \%$ and $1.1 \%(p=0.02475)$ and was higher than $3 / 10$ in $73.3 \%$ and 92.2 $\%(\mathrm{p}=0.0487)$ respectively in G1 and G2 (Figure 5). The complications like secondary cataract and corneal edema were the main causes of non amelioration in visual acuity in each group.

\section{DISCUSSION}

In order to evaluate the new surgical cataract technique (MSICS) which is a variant 
of ECCE sutureless, a prospective, monocentric, descriptive and analytical study has been conducted. This methodology has also been used by some authors either to be compared to MSICS or ECCE with phacoemulsification [3,5,8,9,11-14].

In our study keratometry before and after the operation was not carried because of the lack of equipment. This does not allow us to evaluate the surgically induced astigmatism. Astigmatism is a complication of cataract surgery that can influence functional results $[5-9,15]$. Another limit of our study is the non-computation of implant power for the same reason as before. Thus, patients have been implanted in posterior chamber with rigid implants PMMA power ranging from 21 to 22 diopters. This situation can make our postoperative functional outcomes probably underestimated.

Visual acuity on D45 does not reflect the final visual acuity of the operated eye especially with ECCE, which requires sufficient perspective to stabilize the astigmatogen effect of sutures. Some authors evaluated visual acuity 6 or 12 weeks postoperative $[4,5,8,11-16]$. The ablation of sutures was done on D30 of postoperative in G1. Control on D45 allowed to evaluate visual acuity in both groups. In conditions that were familiar to us, the two techniques were compared in order to determine the best new operative technique to be used in future cataract surgeries in our developing country.

We noted a female predominance in both groups of the study. This observation reinforces the trend generally reported by several authors [5,7,17-19]. Lindfield et al. [20] also observed in a multicentre study in Kenya, Philippines and Bangladesh that more women undergo cataract surgery than men. Women are prevalent in each study group because they have a higher life expectancy than men according to updated data from the general direction of statistics and population in Togo.

In our study, UVA preoperative (Figure 1) was less than $1 / 10$ in $96 \%$ in Group 1 and $90.5 \%$ in Group 2. Gogate et al. [8] reported that the UVA was less than 1/10 in $85.8 \%$ in the group of manual small incision cataract surgery (MSICS) equivalent of MSICS and $87.5 \%$ in that of ECCE. Venkatesh et al. [21] observed that $88.5 \%$ of the patients of their series were operated at the stage of VA less than $1 / 10$. In a study in the United Kingdom percentage of patients operated for cataract at VA less than $1 / 10$ decreased by $15 \%$ in 1997 to $1.6 \%$ in 2000 and finally to $0 \%$ in 2008 [22]. This can be explained by the improvement of technical conditions for carrying out the cataract surgery in line with requirements for visual performance of the population. This context has promoted upward revision of preoperative VA threshold. With MSICS, it will be possible to operate a cataract to a higher VA to $1 / 10$ if the patient is very plaintiff with a guarantee of anatomical and functional results in our countries with limited resources.

The main operative incident reported in our study is the vitreous loss in $3.8 \%$ and $3.3 \%$ respectively in groups 1 and 2 . Our results are slightly lower than the 5\% recommended by WHO [23]. Both techniques have the same risk of vitreous loss. This observation was also made by Gogate et al. [8] but with frequencies of $1.56 \%$ and $1.67 \%$ respectively in the group of MSICS and in that of ECCE on samples of 383 and 358 eyes. In India, George et al. [11], as Gurung et al. [12], in Nepal reported no vitreous loss in both surgical techniques. But it should be noted that the sizes of their samples were 124 and 88 respectively for the two eyes combined techniques.

MSICS gave a better pinhole VA in our series with a statistically significant difference (Figure 5). WHO [23] recommended after cataract surgery, there is less than $5 \%$ with a pinhole VA less than $1 / 10$ and the pinhole VA is greater than $3 / 10$ in the least $90 \%$. MSICS better meets the WHO recommendations in our series. Gogate et al. [24] reported $1.7 \%$ and $1.1 \%$ respectively in MSICS and ECCE in Kenya, Trivedy [25] found that $81.8 \%$ of the operated had an UVA greater than or equal to $3 / 10$ in a 
sample of 368 eyes operated with MSICS. Other authors have also observed that MSICS provides early better visual acuity compared to ECCE $[3,11,12]$. But most of clinicians have also shown that the gap narrows and becomes less significant when we consider the corrected VA.

Early complications were dominated in our series by corneal edema and inflammation (iridocyclitis). It is a transitory edema whose frequencies are slightly higher in the ECCE group than in MSICS respectively of $13.3 \%$ and $9.4 \%$. Gurung et al. [12] also met more corneal edema in their group of ECCE than in the one of MSICS, but with high frequencies of $62 \%$ and $48 \%$. We think that the surgeon's experience has also contributed to the quality of our results. Iridocyclitis in our series was more recurrent in ECCE in such MSICS as noted by Gogate et al. [8] but with a statistically not significant. The occurrence of this inflammation causes a lengthening of topical corticosteroid therapy with increase in the overall cost of cataract surgery. Our study also showed further that MSICS generates slightly less clouding of the posterior capsule than ECCE with 6.1\% against 8.3\%. Ang et al. [7] have observed no difference between the two techniques either $1.1 \%$ or $0.8 \%$.

\section{CONCLUSION}

At the end of this prospective study that compared the extracapsular cataract extraction (ECCE) to the manual sutureless small incision cataract surgery (MSICS), we noted that both techniques offer the same security level because they have the same intraoperative period risk of vitreous loss. In postoperative period, ECCE gives more inflammation than MSICS, which could increase the final cost of cataract treatment. MSICS gives better uncorrected visual acuities compared to ECCE six weeks after surgery. This is an advantage in developing countries where the majority of patients does not have the means to afford the optical corrections after the operation. MSICS gives less secondary cataracts than ECCE. This is an advantage in eye centers in developing countries, where the ndYag laser is often scarce. The MSICS should be promoted to allow its widely use in developing countries because of the lack of human resources, infrastructure, and technology in order to accelerate the fight against blindness from cataract.

\section{REFERENCES}

1. Foster A, Gilbert C, Johnson G. Changing patterns in global blindness: 1998-2008. Community Eye Health. 2008; 21: 37-39. Ref.: https://goo.gl/z7nXmP

2. Ndiaye PA, El Amary K, Seye-Ndiaye C, Demeideros M, Wane AM, et Al. [Scleral mini-incision without ultrasound in the treatment of congenital cataract]. J Fr Ophtalmol. 1999; 22: 347-351. Ref.: https://goo.gl/hkWlH7

3. Ang M, Evans JR, Mehta JS. Manual small incision cataract surgery (MSICS) with posterior intraocular lens versus extracapsular cataract extraction (ECCE) with posterior intraocular lens for age-related cataract. Cochrane Database Sys Rev. 2012; 18: CD008811. Ref.: https://goo.gl/GiH0Q1

4. Muhammad TK, Sanaullah J, Zakir H, Samina K, Muhammad KK, et al. Visual outcome and complications of manual sutureless small incision cataract surgery. Pak J Ophthalmol. 2010; 26: 32-38. Ref.: https://goo.gl/Afb3Z6

5. Ruit S, Tabin G, Chang D, Bajracharya L, Kline DC, et al. A prospective randomized clinical trial of phacoemulsification vs manual sutureless small-incision extracapsular cataract surgery in Nepal. Am J Ophthalmol. 2007; 143: 32-38. Ref.: https://goo.gl/9bjuEC

6. Sherwin JC, Dean WH, Schaefers I, Courtright P, Metcalfe N. Outcomes of manual smallincision cataract surgery using standard 22 dioptre intraocular lenses at Nkhoma Eye Hospital, Malawi. Int Ophthalmol. 2012; 32: 341-347. Ref.: https://goo.gl/L5j1Ga

7. Tabin G, Chen M, Espandar L. Cataract surgery for the developing world. Curr Opin Ophthalmol. 2008; 19: 55-59. Ref.: https://goo.gl/nXo9Ug

8. Gogate PM, Deshpande M, Wormald RP, Deshpande R, Kulkarni SR. Extracapsular cataract surgery 
compared to manual small incision cataract surgery in community eye care setting in western India: a randomized controlled trial. Br J Ophthalmol. 2003; 87: 667-672.

9. Ayena KD, Billong J, Vonor K, Diallo JW, Santos MAK, Maneh N, et al. Assessment of astigmatism in manual and sutureless small incision cataract surgery. New Front Ophthalmol 2015; 1: 14-17. Ref.: https://goo.gl/8NcmYv

10. Chirurgie de la cataracte. In John Sandford-Smith. Chirurgie oculaire sous les climats chauds. Traduit par Olivier Collin et Paddy Ricard. ICEH, Londres, 2006: 81-200.

11.George R, Rupauliha P, Sripriya AV, Rajesh PS, Vahan PV, et al. Comparison of endothelial cell loss and surgically induced astigmatism following conventional extracapsular cataract surgery, manual small incision surgery, and phacoemulsification. Ophthalmic Epidemiol. 2005; 12: 293-297. Ref.: https://goo.gl/plMzln

12.Gurung A, Karki DB, Shreshta S, Rijal AP. Visual outcomes of conventional extracapsular cataract extraction with posterior chamber intraocular lens implantation versus manual small incision cataract surgery. Nep J Ophthalmol. 2009; 1: 13-19. Ref.: https://goo.gl/61K4iT

13.Sharma RL, Mahajan D, Sharma K. SICS tunnel construction with oblique limbal stab incision and its effectiveness in self-sealing, nucleus delivery and astigmatism minimal duration cataract surgery. J Ocul Dis Therapeut. 2014; 2: 55-63. Ref.: https://goo.gl/hv6seM

14.Gogate PM, Kulkani SR, Krishnaiah S, Deshpande RD, Joshi SA, et al. Safety and efficacy of phacoemulsification compared with manual small-incision cataract surgery by a randomized controlled clinical trial: six week results. Ophthalmology. 2005; 112: 869-874. Ref.: https://goo.gl/NImrqc

15.Devendra J, Agarwal S, Singh PK. A comparative study of clear corneal phacoemulsification with rigid IOL versus SICS; the preferred surgical technique in low socio-economic group patients of rural areas. J Clin Diagnos Res. 2014; 8: 1-3. Ref.: https://goo.gl/OyxkDE

16. Khandekar RB, Jain BK, Sudhan AK, Pandey KP. Visual acuity at 6 weeks after small incision cataract surgery and role of audit in predicting visual acuity. Eur J Ophthalmol. 2010; 20: 345-352. Ref.: https://goo.gl/c03V4S

17.Shah SP, Gilbert CE, Razavi H, Turnerb EL, Lindfield RJ. Preoperative visual acuity among cataract surgery patients and countries' state of development: a global study. Bull World Health Organ. 2011; 89: 749-756. Ref.: https://goo.gl/rTr64R

18. Hennig A. Chirurgie de la cataracte sans suture et sans phacoémulsification: une solution pour réduire la cécité par cataracte dans le monde? RSOC. 2005; 2: 4-5. Ref.: https://goo.gl/P3PiMl

19.Amza A, Djibo H, Yacoubou S, Abdoulaye SH. Résultats de la chirurgie de la cataracte par la technique de phacoalternative au Niger. Ann Univ Abdou Moumouni. 2011; XII-A: 49-56.

20.Lindfield R, Kuper H, Polack S, Eusebio C, Mathenge W, et al. Outcome of cataract surgery at one year in Kenya, the Philippines and Bangladesh. $\mathrm{Br} \mathrm{J}$ Ophthalmol. 2009; 93: 875-880. Ref.: https://goo.gl/IER4J5

21. Venkatesh R, Muralikrishnan R, Balent LC, Prakash SK, Prajna NV. Outcomes of high volume cataract surgeries in a developing country. Br J Ophthalmol. 2005; 89: 1079-1083. Ref.: https://goo.gl/MvhMFV

22. Shah SP, Gilbert CE, Razavi H, Turnerb EL, Lindfield RJ. Preoperative visual acuity among cataract surgery patients and countries' state of development: a global study. Bull World Health Organ. 2011 89: 749-756. Ref.: https://goo.gl/rTr64R

23. Limburg H, Foster A, Vaidyanathan K, Murthy GV. Monitoring visual outcomes of cataract surgery in India. Bull World Health Organ. 1999; 77: 455-460. Ref.: https://goo.gl/1oaPLt

24.Gogate PM, Deshpande M, Wormald RP. Is manual small incision cataract surgery affordable in the developing countries? A cost comparison with extracapsular cataract extraction. $\mathrm{Br} \mathrm{J}$ Ophthalmol. 2003; 87: 843-846. Ref.: https://goo.gl/JXT4xv

25. Trivedy J. Outcomes of high volume cataract surgeries at a Lions Sight First Eye Hospital in Kenya Nepal J Ophthalmol. 2011; 3: 31-38. Ref.: https://goo.gl/680f5J 